\title{
Radiographic Diagnosis of Osteochondritis Dissecans of the Temporomandibular Joint: Two Cases
}

\author{
Melda Misirlioglu Mehmet Zahit Adisen Selmi Yilmaz \\ Department of Oral and Maxillofacial Radiology, Faculty of Dentistry, Kırıkkale University, Kırıkkale, Turkey
}

\section{Key Words}

Osteochondritis dissecans · Synovial chondromatosis .

Panoramic radiography . Cone-beam computed tomography

\begin{abstract}
Objective: To present two cases of osteochondritis dissecans (OCD) in temporomandibular joints (TMJs) evaluated by panoramic radiography and cone-beam computed tomography (CBCT). Clinical Presentation and Intervention: Two patients were referred to the Oral and Maxillofacial Radiology Clinic with pain, preauricular tenderness on the TMJ region and limitation of mandibular movements. An earlier panoramic radiograph revealed radiopaque lesions adjacent to the condyles. CBCT images were obtained from patients to assess the radiopacities. The CBCT scan detected irregular-type radiopaque lesions on anterior and superior aspects of the right condyle as well as degenerative osseous changes on both TMJs. Conclusion: The CBCT images revealed degenerative osseous changes and loose bodies on TMJs. The lesions were diagnosed as OCD with the help of trauma history, as well as clinical and radiographic findings.
\end{abstract}

(c) 2014 S. Karger AG, Basel

\begin{tabular}{ll}
\hline KARGER & $\begin{array}{l}\text { (1) 2014 S. Karger AG, Basel } \\
1011-7571 / 14 / 0236-0580 \$ 39.50 / 0 \quad \text { Karger }\end{array}$ \\
E-Mail karger@karger.com & $\begin{array}{l}\text { This is an Open Access article licensed under the terms of the } \\
\text { www.karger.com/mpp }\end{array}$ \\
$\begin{array}{l}\text { Creative Commons Attribution-NonCommercial 3.0 Un- } \\
\text { ported license (CC BY-NC) (www.karger.com/OA-license), } \\
\text { applicable to the online version of the article only. Distribu- } \\
\text { tion permitted for non-commercial purposes only. }\end{array}$
\end{tabular}

\section{Introduction}

Osteochondritis dissecans (OCD) is a joint disorder characterized by bony necrosis followed by healing [1]. It is often a consequence of an acute osteochondral fracture, where the depressed cortical bone fails to reunite with adjacent normal bone [2]. One of the characteristic radiographic features is the appearance of loose bodies dislodged from defects seen on the condylar heads [3]. The OCD is most often reported in the larger joints of the body, including the knee, elbow, hip, wrist and ankle. Involvement of the temporomandibular joint (TMJ) is rare [4]. The clinical features of OCD are characterized by pain, intracapsular sounds (clicking, crepitation or both) and limitation of joint movement [2]. Accurate diagnosis of OCD is based on history and clinical, radiographic and microscopic examination. This paper presents two cases of OCD in TMJ evaluated by panoramic radiography and cone-beam computed tomography (CBCT).

\section{Case Reports}

Case 1

A 75-year-old man was referred to the Oral and Maxillofacial Radiology Clinic with pain and preauricular tenderness in the right TMJ regions, which had made him unable to open his mouth 


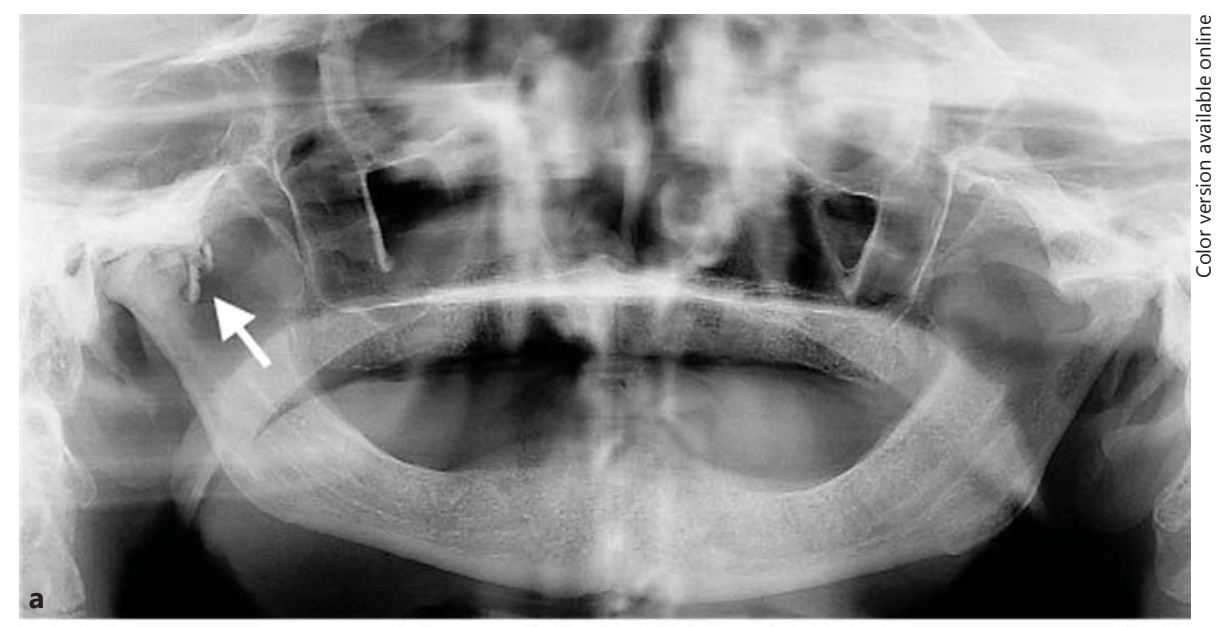

Fig. 1. a Panoramic radiograph of case 1 . Arrow shows loose bodies anterior to the mandibular condyle at the right side. b Cross-sectional sagittal view images; arrows show irregular-type loose bodies on anterior and superior aspects of the right condyle.

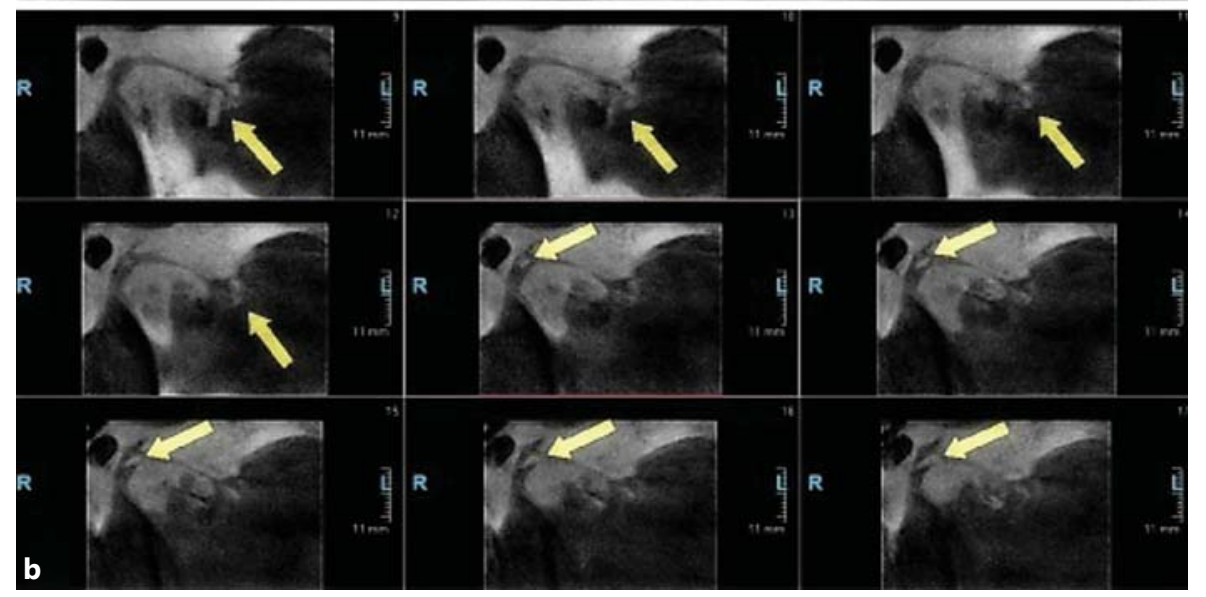

for 5 years. The patient had no history of trauma, rheumatoid arthritis or any other systemic diseases but had been using complete denture for about 15 years. Physical examination revealed joint crepitus and limitation of mandibular movement. An earlier panoramic radiograph (fig. 1a) revealed radiopacities (loose bodies) anterior to mandibular condyle on the right side. Pax Uni3D (Vatech, Seoul, Korea) was used to obtain CBCT images (50-90 kVp, $4-10 \mathrm{~mA}, 10 \mathrm{~s}, 50 \times 50 \mathrm{~mm}$ FOV). The CBCT scan detected irregular-type radiopaque lesions on anterior and superior aspects of the right condyle as well as degenerative osseous changes on both TMJs (fig. 1b).

\section{Case 2}

A 48-year-old man was also referred to the Oral and Maxillofacial Radiology Clinic with pain, preauricular tenderness in the TMJ regions and limitation of mandibular movement for 24 years. The patient had no systemic diseases but he had a history of trauma: he had fallen from a roof 24 years previously, which resulted in a fractured jaw treated with intermaxillary fixation. However, after treatment the patient developed a permanent limitation of mandibular movement. Physical examination revealed joint crepitus and a limitation of mandibular movement, and an earlier panoramic radiograph revealed degenerative osseous changes (fig. 2a). $\mathrm{CBCT}$ images were obtained, and an irregular-type radiopaque le-

Osteochondritis Dissecans of the

Temporomandibular Joint sion was detected on the superior aspect of the right condyle as well as degenerative osseous changes on both TMJs (fig. 2b). The lesions were diagnosed as OCD with the help of trauma history and the radiographic findings including degenerative changes and radiopaque lesions (loose bodies) in TMJs. Both patients were referred to the Department of Oral and Maxillofacial Surgery for biopsy and treatment and to MRI for advanced imaging, but due to their economic status, they declined intervention.

\section{Discussion}

Two rare cases of OCD with loose bodies on TMJs are reported in this paper. OCD needs to be differentiated from other conditions that show osteochondral loose bodies in joints including intracapsular fractures, osteoarthritis, synovial chondromatosis, rheumatoid arthritis and chondrocalcinosis (gout) [5].

The TMJ is infrequently affected by a tumour or tumour-like lesion; however, synovial chondromatosis is the most common neoplastic lesion of the joint [6]. 
Fig. 2. a Panoramic radiograph of case 2 . Arrow shows loose body superior to the mandibular condyle at the right side. b Cross-sectional sagittal view images; arrows show loose body on superior aspect of the right condyle.
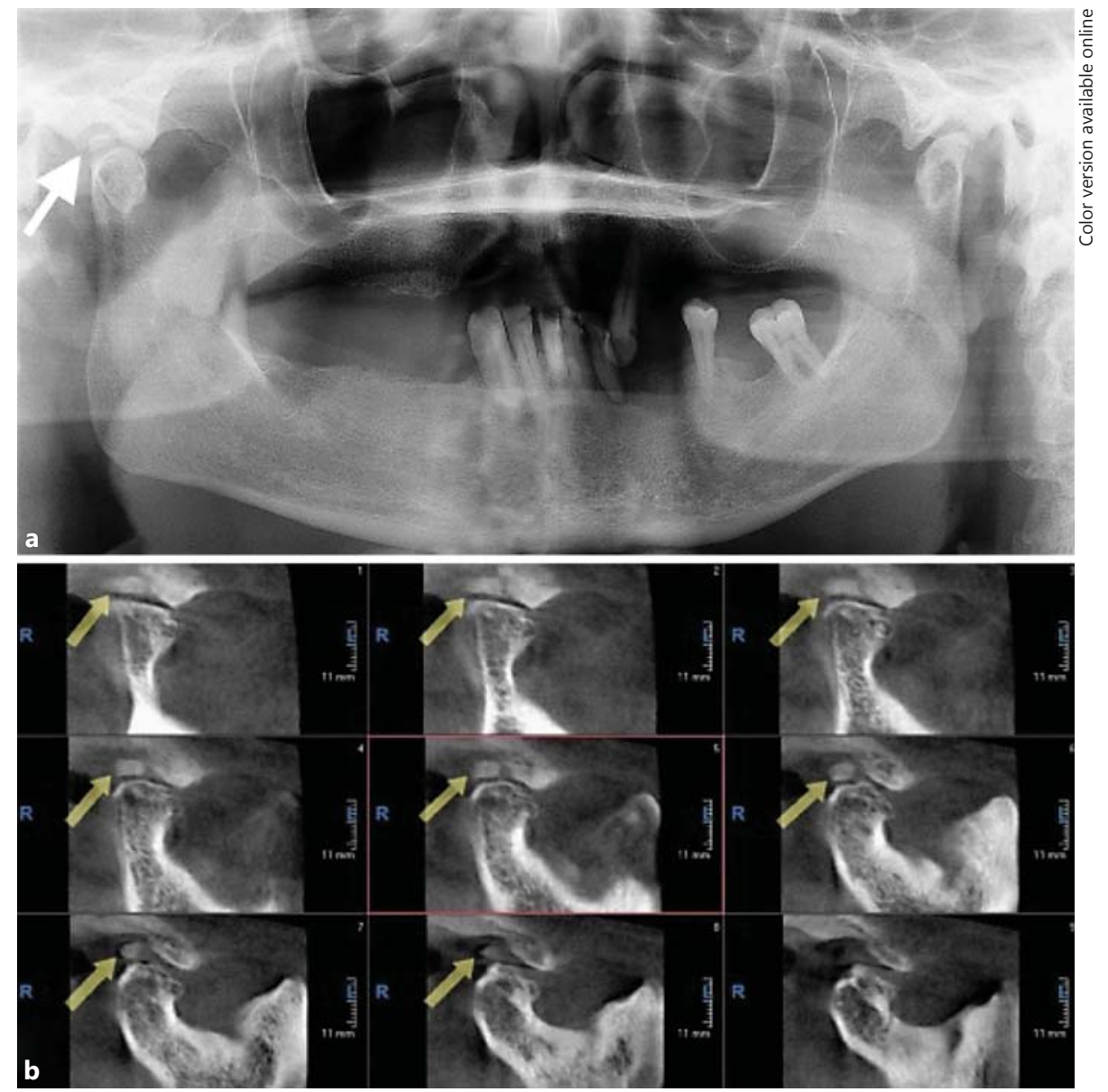

Pathologically, synovial chondromatosis is characterized by multiple cartilaginous loose bodies formed in the synovial membrane. Loose bodies are regular in shape and involve only the superior joint space. Symptoms typically include progressive swelling in addition to pain, intracapsular sounds and limitation of mandibular movement [5]. However, in our cases there was no swelling in the symptoms, and irregular-type loose bodies were detected on both anterior and superior aspects of the condyle in the first case. Also, there was a history of trauma in the second case. Furthermore, the size of the calcifications did not favour a diagnosis of osteoarthritis, and no predisposing factors were evident for chondrocalcinosis [5]. These features led us to the diagnosis of OCD in these patients.

The aetiology of OCD is unclear, but it may involve repeated physical trauma, ischaemia (restriction of blood flow), hereditary and endocrine factors, haematologic disorders, chemotherapeutic agents, avascular necrosis (loss of blood flow), and anomalies of bone formation and familial predisposition [2]. In the first case, repeated trauma to the jaws due to a long period of complete denture usage and the resulting blunt force transmitted to the joint could have been an initiating factor in the formation of loose bodies of the TMJ. On the other hand, the patient history in the second case suggested that the loose bodies are a consequence of acute osteochondral fracture.

The diagnosis of OCD in TMJ can be made by panoramic radiography, CT, CBCT and MRI $[1,4]$. Although panoramic radiography plays a fundamental role, as it is one of the most frequently employed dental radiographic method [1], spatial information in all 3 dimensions was critical in establishing a diagnosis [5]. The serial images provided with a CT scan make it possible to identify the exact locations and characteristics of loose bodies in the TMJ complex that cannot be detected with panoramic radiography. In comparison to CT, CBCT offers the advan- 
tages of significantly lower radiation exposure, reasonably short scanning times, and a more compact design with acceptable accuracy [6]. MRI is also useful in demonstrating internal derangement of the TMJ. Intra-articular loose bodies, expansion of joint capsule and fluid accumulation within the joint space can be directly depicted by MRI [2]. However, high cost and relatively long imaging times limit routine use [5].

\section{Conclusion}

The utility of a CBCT in the diagnosis of a lesion involving the TMJ is emphasized in this study. Degenerative osseous changes and loose bodies were detected on TMJs with the aid of CBCT images. The lesions were diagnosed as OCD due to trauma history, and clinical and radiographic findings.

\section{References}

1 Campos PS, Freitas CE, Pena N, et al: Osteochondritis dissecans of the temporomandibular joint. Dentomaxillofac Radiol 2005;34: 193-197.

2 Schellhas KP, Wilkes CH, Fritts HM, et al: MR of osteochondritis dissecans and avascular necrosis of the mandibular condyle. AJR Am J Roentgenol 1989;152:551-560.
3 Hixon AL, Gibbs LM: What should I know about osteochondritis dissecans? Am Fam Physician 2000;61:158.

4 Orhan K, Arslan A, Kocyigit D: Temporomandibular joint osteochondritis dissecans: case report. Oral Surg Oral Med Oral Pathol Oral Radiol Endod 2006;102:41-46.
5 Balasundaram A, Geist JR, Gordon SC, et al: Radiographic diagnosis of synovial chondromatosis of the temporomandibular joint: a case report. J Can Dent Assoc 2009;75:711714.

6 Abuabara A, Miles DA, Cruz GV, et al: Radiological study of three cases of loose bodies in the temporomandibular joint. Braz J Oral Sci 2010;9:133-136. 